\title{
Desigualdades territoriales de las ciudades multiculturales. El caso del estado de Oaxaca, México
}

\section{Territorial inequalities of multicultural cities. The case of the state of Oaxaca, Mexico}

\author{
Julita Moreno Avendaño* \\ Andrés Enrique Miguel-Velasco* \\ Maribel Pérez Pérez* \\ Christian Martínez Olivera* \\ Karina Aidee Martínez García*
}

\begin{abstract}
Using the Social Gap Index and the Gini index, intra-urban inequalities in the main cities of the state of Oaxaca during 1990-2010 are analyzed. The results show that the greatest weight when measuring inequality is held by the quality of housing, the level of education, and to a lesser extent, the quantity of native population, showing different dynamics in the cities, with an upward trend in inequality. It is concluded that the current development process in these cities has not been resolved and is increasing inequality, preferably in the cities with a smaller native population.
\end{abstract}

Keywords: intra-urban inequality, social backwardness, Gini index, multicultural cities.

\section{Resumen}

A partir del Índice de Rezago Social y el Índice de Gini se analizan las desigualdades intraurbanas en las principales ciudades del estado de Oaxaca durante 1990-2010. Los resultados muestran que al medir la desigualdad, los factores más visibles son la calidad de la vivienda, el nivel educativo y, en menor medida, la cantidad de población originaria, los cuales revelan dinámicas diferentes en las ciudades con una tendencia a acrecentar la desigualdad. Se concluye que el proceso de desarrollo vigente en las ciudades estudiadas no se ha resuelto y que incrementa la desigualdad en las ciudades que poseen una menor población originaria.

Palabras clave: desigualdad intraurbana, rezago social, índice Gini, ciudades multiculturales.

* Instituto Tecnológico de Oaxaca, México, correo-e: julitamorenoave@gmail.com, andres. miguel@itoaxaca.edu.mx,mary01758@hotmail.com, christianolivera26@gmail.com y aidee1005@ gmail.com 


\section{Introducción}

La estrategia de urbanización desarrollada en las ciudades en las últimas décadas está orientada a la concentración de infraestructura, bienes y servicios, así como a la apertura comercial, el libre mercado y la integración a la globalización, lo cual aumenta la concentración y transforma los paisajes y las condiciones de vida de las localidades. El intenso ritmo de urbanización, la falta de planeación, así como las rápidas tasas de crecimiento poblacional son, entre otras, las principales causas para que este crecimiento se despliegue de manera desordenada y desequilibrada en las ciudades. Estos procesos, tanto económicos como sociales, reconfiguran los espacios, su estructura y su funcionamiento (Vélez y Mejía, 2016) y ocasionan grandes desigualdades al interior de ellas. Ahora bien, si se parte de que el vocablo ciudad proviene del latín civitas y que se refiere a ésta como el área urbana que presenta una alta densidad de población, conformada por habitantes que no se dedican a las actividades agrícolas, la Conferencia Europea de la Estadística de Praga advierte que una ciudad es una aglomeración de más de 5000 habitantes donde menos del 25\% de la población se dedica a la agricultura (Miguel-Velasco et al., 2016). Por otra parte, la ciudad multicultural es un concepto que contribuye a comprender el carácter histórico de la reconfiguración de la ciudad contemporánea, especialmente en territorios que integran el estado de Oaxaca (México), los cuales se analizan en el presente artículo, cuyo objetivo es generar propuestas de gestión de las diferencias culturales para enfrentar el impacto demográfico, social y cultural de los flujos migratorios y su "inclusión en el desarrollo de la ciudad" (Villegas, 2016) y que en una instancia analítica puede visualizarse a través de la cantidad de población originaria que resida en la ciudad.

Derivado de lo anterior, en el presente artículo se analizan las desigualdades intraurbanas de las principales ciudades del estado de Oaxaca durante 1990-2010 (mapa 1), a partir del índice de rezago social y la aplicación del Índice de Gini. Se plantea como hipótesis que la cantidad de población originaria que se asienta en las ciudades tiene mayor peso estadístico en las desigualdades intraurbanas que el manifestado por los indicadores del rezago social.

Se toman en cuenta aquellas ciudades cercanas con más de 15,000 habitantes que por su ubicación geográfica y su importancia funcional y económica fueron seleccionadas para el estudio. En total son 17 ciudades, entre las que destacan dos zonas metropolitanas, cada una de ellas, pertenecientes a las ocho regiones del estado de Oaxaca, por lo cual presentan diferentes condiciones socioeconómicas, políticas y culturales, lo que hace más atractivo su análisis. 


\section{Mapa 1}

\section{Ubicación geográfica de las ciudades multiculturales del estado de Oaxaca, México}

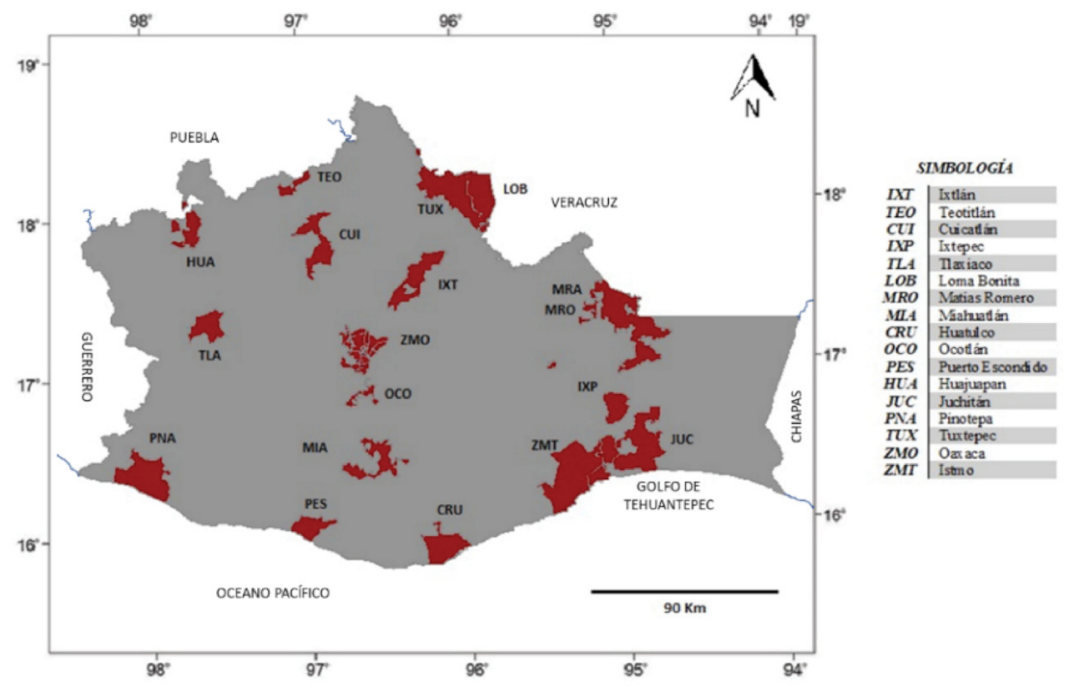

Nota: En el cuadro que acompaña al mapa se indica el nombre de las ciudades y sus abreviaturas con las que se identificarán en el presente análisis.

Fuente: elaboración propia con apoyo del software Mapa Digital Versión 6.1.0 (Inegi, 2013).

\section{Desigualdad urbana}

En las ciencias sociales, la desigualdad se define como una desproporción económica, política o social en la que se encuentran unos individuos frente a otros. Por ejemplo, desde el aspecto económico, el Banco Mundial la define como "la dispersión de la distribución sea el ingreso, como el consumo o de algún otro indicador de bienestar o atributo de una población" (Peppino, 2004: 4).

Sin embargo, a pesar de que el campo de investigación económica ha dominado el tema, Reygadas (2008) expone que las desigualdades son multidimensionales y no pueden tratarse desde un solo enfoque. Inzulsa a su vez, expresa:

La desigualdad, por consiguiente, no se expresa solamente con la enorme diversidad adquisitiva de los ingresos de las personas, sino que se deriva en la discriminación de la clase, de raza, de género, de origen geográfico, de distinta capacidad física, etc., que practicadas de manera categórica, la convierten en un fenómeno multidimensional y la hacen incompatible con nuestros ideales (2011: 15). 
Por ello, en el presente artículo se estudia la desigualdad urbana desde un enfoque territorial, desde el cual las desigualdades territoriales se expresan "como las disparidades en cuanto a la distribución espacial de unos recursos que son escasos, una manera desigual de distribuirlos, con excedente y despilfarros en las sociedades desarrolladas y déficits hirientes que están dominados por los paisajes de pobreza" (George, 1983: 11). Por su parte, Pamplona (2005) manifiesta que éstas son las desigualdades socioeconómicas e incluso socioambientales, condicionadas territorialmente, y que marcan la diferencia entre territorios, cuyas fronteras están definidas por una lógica administrativa o algún fin político.

Ahora bien, la relación entre la segregación residencial y las desigualdades sociales radica en que la primera es un fenómeno espacial, en tanto que la segunda es un fenómeno social (Sabatini et al., 2001). El primer fenómeno está determinado por la movilidad social (i.e., el ascenso en la pirámide social), el nivel de ingresos y las identidades étnicas-colectivas que conviven en el espacio, y el segundo es un mecanismo de autoprotección y autoexclusión que implica el repliegue, agrupamiento y distanciamiento al que recurren los grupos sociales para resguardar sus identidades en procesos de formación o en riesgo.

Para Sabatini et al., los estudiosos de la ciudad pueden asumir un sesgo metodológico-conceptual de carácter reduccionista, cuando asumen que el aumento de la segregación urbana tiene como consecuencia el aumento de la desigualdad social, es decir, "suponen que la segregación espacial es un simple reflejo de las diferencias sociales. [Y, por tanto, asumen que] Habría una relación simétrica o 'de espejo' entre desigualdades sociales y segregación residencial” (2001: 23). Esta confusión, muchas veces derivada del empleo de mapas temáticos o planos de colores que privilegian la interpretación estática y estructural de las ciudades, debe ser cuidadosamente evitada por los geógrafos, planificadores urbanos, arquitectos y otros investigadores.

El impacto de la desigualdad en el espacio es el origen de territorios significativamente rezagados, caracterizados por menor oportunidad de educación, capacitación, empleo y acceso a la salud y, por tanto, menor calidad de la fuerza de trabajo y menor productividad, donde al haber cierto nivel de pobreza e inequidad crean un entorno favorable para la violencia y el conflicto social extremo. De acuerdo con Ayala (2012), esto provoca que no sea lo mismo vivir en un lugar u otro, a tal grado que las condiciones del lugar de residencia determinan las condiciones socioeconómicas y las posibilidades de acceso a bienes y servicios del residente que les ayudan a garantizar cierta calidad de vida. A escala urbana, Soja (2009) considera que el desarrollo desigual puede considerarse el resultado de patrones específicos de distribución de los recursos valorados socialmente, 
como la dotación de infraestructura y equipamiento urbano, por ejemplo; o como el resultado de procesos subyacentes relativos a las decisiones e intereses de los sujetos sociales que son injustas en sí mismas, en ocasiones bajo escenarios de discriminación hacia ciertos grupos sociales entre los cuales se incluyen los grupos originarios o en los que resaltan las diferencias étnicas.

En México y en el mundo, con la nueva reestructuración del orden mundial derivado del proceso de globalización y su impacto, se generó un conjunto de diversos procesos sociales y económicos que reconfiguraron las ciudades, su estructura y funcionamiento (Vélez y Mejía, 2016); dichos procesos se desarrollan principalmente en los espacios urbanos, en donde coincide la mayor concentración de actividades económicas, sociales y políticas. Esta nueva reconfiguración, el crecimiento exponencial de las ciudades debido a la migración (sobre todo de la población originaria de las áreas rurales a la ciudad), así como la falta de planeación, la escasa regulación, la especulación del suelo y la compra-venta barata de lugares en la periferia frecuentemente en zonas no aptas para urbanizar y edificar generan nuevas y diferentes desigualdades en el acceso de bienes y servicios al interior de la ciudad, propician que algunas zonas se vean más beneficiadas que otras.

Por tanto, derivado de las múltiples dinámicas y procesos de tipo político, social, económico, demográfico y urbano desarrollados en los distintos territorios, entre ellos el territorio urbano, sería muy limitante definir y medir la desigualdad desde el enfoque económico, por lo que es más oportuno abordarla desde un enfoque multidimensional que englobe diversos elementos que interfieran y mejoren la calidad de vida de las personas. Desde esta perspectiva, la desigualdad urbana se entiende como

la distribución inequitativa de elementos indispensables para el mejoramiento de la calidad de vida y desarrollo de las personas, tales como el acceso a la educación, la salud, servicios básicos y de saneamiento, trabajo, ingreso, vivienda, alimentación, participación, etc., es decir, de todo aquel elemento que pueda mejorar las posibilidades de las personas para acceder a distintas oportunidades y les permita obtener así un nivel de bienestar aceptable (Moreno, 2019: 91).

\subsection{Análisis y medición de la desigualdad intraurbana}

Las desigualdades expresadas en el ámbito territorial no pueden explicarse únicamente como resultado del desempeño de variables económicas, aunque debe quedar claro que estas variables condicionan, pero nunca determinan el crecimiento y desarrollo en el territorio. Es importante considerar que son muchos los factores que intervienen en el proceso de surgimiento y agudización de las desigualdades y es preciso delimitarlos 
para así poder determinar cuáles podrían ser las posibles causas estructurales que conllevan a que las distintas ciudades sufran procesos de fragmentación espacial que aíslen a ciertos grupos cada vez más hasta el grado de diferenciar, segregar e incluso excluir a barrios o zonas ricas y pobres (Arias, 2005).

Los primeros estudios que tomaron en cuenta el problema de la desigualdad en el espacio urbano lo hicieron desde el enfoque económico, destacando cómo ciertos elementos influyen y determinan la distribución del ingreso en el medio urbano y cómo se explica la desigualdad bajo estos argumentos (Harvey, 1973). También estos análisis dieron la pauta para considerar las escalas de cómo debería medirse este tipo de desigualdad, recomendando medirla a escalas de barrios o por zonas mucho mejor definidas, a partir de los datos disponibles en lo que se refiere al origen geográfico o nacional de los habitantes, las actividades profesionales, los salarios, las rentas, la tasa de alquiler y la calidad de los equipamientos, etc. (George, 1983).

Desde el enfoque de la sociología urbana y la ecología factorial de la escuela de Chicago, Fernández-García et al. (2018) hacen una revisión teórica exhaustiva de los diversos trabajos realizados en cuanto a la medición de la desigualdad en los espacios urbanos. La mayoría de los trabajos revisados apuestan por la elaboración de un índice sintético que integre diversas características de los espacios, mediante el cual se diferencien las distintas zonas de la ciudad según sus condiciones socioeconómicas. Según Fernández-García et al., "estos acercamientos al análisis de la desigualdad urbana han partido de la premisa de que el estatus socioeconómico, como resumen del conjunto de recursos que poseen los residentes, es el factor más importante para analizar la desigualdad socioespacial” (2018: 52).

Desde esta perspectiva, los indicadores comúnmente utilizados para conformar los índices sintéticos están relacionados con los siguientes aspectos: pobreza (ingreso), exclusión social (empleo, educación, salud), habitabilidad (condiciones y equipamientos de viviendas y edificios, servicios básicos, hacinamiento, etc.), espacio público (zonas de recreación) y calidad ambiental (contaminación, uso de energía eléctrica, etc.). Igualmente, la composición étnica ha sido considerada un importante indicador en muchos de los estudios de la desigualdad, no sólo en el ámbito urbano, ya que éste puede estimarse como un factor de exclusión social (Fernández-García et al., 2018). El hecho de pertenecer a una población originaria se traduce en mayor probabilidad de ser excluidos de aspectos como la educación, la salud, una buena alimentación, la seguridad social, el acceso a políticas sociales, así como mayores niveles de pobreza y rezago social (Puyana, 2018; Singer, 2014; Reygadas, 2008). Si los índices mencionados muestran mucha variabilidad entre las zonas, la ciudad se observará más heterogénea y, 
por lo tanto, se hablará de mayor desigualdad. Los resultados de la aplicación de dichos índices, comúnmente, han sido utilizados para la identificación de las zonas de atención prioritaria o de mayor vulnerabilidad, que requieren de intervención a través de políticas públicas para su mejora.

\subsection{El rezago social como indicador de las desigualdades intraurbanas}

El presente artículo propone el uso del Índice de Rezago Social (IRS) como indicador para medir las desigualdades en las ciudades. Este indicador surge en México a partir de la promulgación de la Ley General de Desarrollo Social (DOF, 2004). En dicha ley, en el capítulo VI de la Medición y Definición de la pobreza se asentó que es el Consejo Nacional de Evaluación de la Política de Desarrollo Social (Coneval) el encargado del establecimiento de los lineamientos y criterios para la medición de la pobreza y, de acuerdo con el artículo 36, sugiere tomar en cuenta los siguientes indicadores: I. Ingreso corriente per cápita, II. Rezago educativo promedio en el hogar, III. Acceso a los servicios de salud, IV. Seguridad social, V. Calidad y espacios en la vivienda, VI. Acceso a los servicios básicos en la vivienda, VII. Acceso a la alimentación y VIII. Grado de cohesión social. De tal modo que el Coneval establece medir la pobreza con base en tres elementos: bienestar económico, derechos sociales y cohesión territorial (DOF, 2010).

El rezago social surge como uno de los elementos principales para la medición de la pobreza multidimensional, mismo que corresponde a la parte de los derechos sociales. A pesar de que sólo representa las carencias sociales de un territorio, éste es considerado un indicador muy importante relacionado con el desarrollo social del país, ya que está integrado por variables como el acceso a la educación, acceso a servicios de salud, servicios básicos, espacio y calidad en las viviendas, así como activos del hogar (Coneval, 2010), y todo ello en conjunto permite ordenar las diversas zonas del país y observar sus diferencias en función del acceso a los beneficios del desarrollo social (Benita y Gómez, 2013).

Aunque este indicador es muy parecido al método de Necesidades Básicas Insatisfechas (NBI) debido a los indicadores que considera, el Índice de Rezago Social (IRS) está mejor complementado ya que, a diferencia del primero, éste integra más información en cuanto al aspecto educación y toma en cuenta el acceso a la salud y los activos en el hogar; indicadores ausentes en el método NBI. Por otra parte, el NBI es un método de medición de la pobreza, mientras que el IRS es sólo un índice para medir la pobreza a través del enfoque multidimensional trabajado en México. Por sí solo, permite medir el grado de carencias sociales de cada territorio y 
tiene la ventaja de que puede desagregarse a nivel estatal, municipal y AGEB. Además, facilita la identificación de zonas prioritarias y contribuye con la generación de datos para la toma de decisiones en materia de política social, especialmente para analizar la desigualdad de coberturas sociales que subsisten en el territorio nacional (Coneval, 2007).

Los indicadores que propone el Coneval para la estimación de este índice varían según el nivel geográfico de desagregación. Para el nivel AGEB considera los expresados en la figura 1 .

Figura 1

Dimensiones e indicadores del índice de rezago social a nivel AGEB

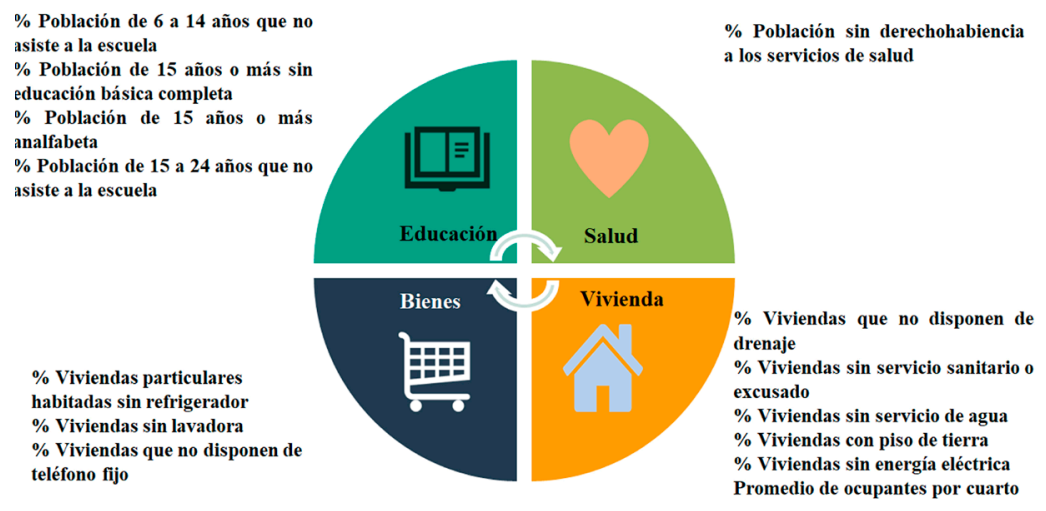

Nota: Debido a la carencia de datos a nivel AGEB para el periodo evaluado no se toman en cuenta los siguientes indicadores: Población de 15 ańos a 24 años que no asiste a la escuela (\%), Viviendas que no disponen de teléfono fijo (\%).

Fuente: elaboración propia con base en Coneval (2007).

En este artículo, además de considerar los indicadores presentados en la figura 1, se integra un indicador de tenencia de la vivienda debido a la importancia que tiene ésta, tanto en el bienestar social como familiar de las personas, ya que contar con una vivienda propia genera beneficios económicos para la familia así como para la sociedad, pues promueve y consolida el desarrollo de las áreas donde se localizan.

Sería ideal que este índice estuviera mejor complementado, debido a la ausencia de información en la escala de AGEB, que es la escala con la que se propone hacer el análisis, y es complicado agregar más indicadores. Sin embargo, este índice contiene muchos elementos que dan cuenta del progreso del desarrollo territorial y social de una zona específica. 


\section{Metodología}

\subsection{Delimitación espacial y temporal}

El análisis del presente artículo es retrospectivo y se realizó para el periodo 1990-2010, debido a que en este rango temporal los datos existentes están desagregados a nivel de AGEB, que es la unidad básica del análisis realizado, y comprende el análisis de 17 ciudades del estado de Oaxaca seleccionadas bajo los criterios especificados en la tabla 1 . Se les considera a estas ciudades como región socioeconómica estatal debido a que forman parte de una concentración económica, cultural y política en cada una de las ocho regiones del estado de Oaxaca.

\section{Tabla 1}

\section{Criterios de elección de las ciudades}

\begin{tabular}{cl}
\hline \multicolumn{1}{c}{ Criterios } & \multicolumn{1}{c}{ Elección de las ciudades } \\
\hline Elegibilidad & $\begin{array}{l}\text { Ciudades del estado de Oaxaca mayores o cercanas a 15,000 habitantes } \\
\text { y que sean lugar central una región socioeconómica estatal. }\end{array}$ \\
Inclusión & $\begin{array}{l}\text { Las ciudades del estado de Oaxaca basadas en una regionalización mixta } \\
\text { (administrativa-nodal-homogénea). Ciudades mayores a 15,000 habi- } \\
\text { tantes y localidades que sean lugar central de una región socioeconómica } \\
\text { estatal. }\end{array}$ \\
Exclusión & $\begin{array}{l}\text { Ciudades menores a 15,000 habitantes y que no sean lugar central de } \\
\text { una región socioeconómica estatal. }\end{array}$ \\
Eliminación & $\begin{array}{l}\text { Ciudades menores a 15,000 habitantes que no sean lugar central de } \\
\text { una región socioeconómica estatal y que carezcan de información del } \\
\text { problema analizado o que no se justifiquen por una regionalización } \\
\text { (administrativa-nodal-homogénea). }\end{array}$ \\
\hline
\end{tabular}

Fuente: Pérez (2018).

\subsection{Procedimiento}

Para la medición de la desigualdad se aplicó el Índice de Gini a los valores del rezago social, instrumento con el cual se mide cualquier forma de distribución desigual. Para el cálculo del Índice de Rezago Social se utilizó la técnica estadística de componentes principales, que permitió combinar información de indicadores de carencias en un índice que sintetiza numéricamente diferentes dimensiones de la pobreza (Coneval, 2007). El cálculo del Índice de Rezago Social se realizó en el nivel de AGEB ${ }^{1}$ urbano y se tomaron en cuenta los indicadores mostrados en la tabla 2.

\footnotetext{
${ }^{1}$ Extensión territorial ocupada por un conjunto de manzanas que, generalmente, son de 1 a 50 , y son delimitadas por calles, avenidas, andadores o cualquier otro rasgo fácil de identificar en el terreno y cuyo suelo sea, principalmente, habitacional, industrial, de servicio y comercial.
} 
Tabla 2

Variables e indicadores del índice de rezago social

\begin{tabular}{|c|c|c|c|}
\hline Dimensión & Subdimensión & & Indicador \\
\hline \multirow[t]{6}{*}{ Económica } & Riqueza & Tenencia de la vivienda & $\%$ Viviendas rentadas \\
\hline & & & $\begin{array}{l}\text { \% Población de } 6 \text { a } 14 \\
\text { ańos que no asisten a la } \\
\text { escuela }\end{array}$ \\
\hline & Educación & Rezago Educativo & $\begin{array}{l}\text { \% Población analfabeta } \\
\text { de } 15 \text { años o más }\end{array}$ \\
\hline & & & $\begin{array}{l}\text { \% Población de } 15 \text { años } \\
\text { y más con educación } \\
\text { básica incompleta }\end{array}$ \\
\hline & Salud & Acceso a servicios de salud & $\begin{array}{l}\text { \% Población sin derecho- } \\
\text { habiencia a servicios de } \\
\text { salud }\end{array}$ \\
\hline & & & $\%$ Viviendas sin drenaje \\
\hline \multirow[t]{7}{*}{ Social } & \multirow{7}{*}{ Viviendas } & \multirow{3}{*}{ Servicios Básicos } & $\begin{array}{l}\% \text { Viviendas sin energía } \\
\text { eléctrica }\end{array}$ \\
\hline & & & $\begin{array}{l}\% \text { Viviendas sin servicio } \\
\text { de agua }\end{array}$ \\
\hline & & & $\begin{array}{l}\% \text { Vivienda sin excusado } \\
\text { o sanitario }\end{array}$ \\
\hline & & \multirow{2}{*}{ Calidad de las viviendas } & $\begin{array}{l}\% \text { Vivienda con piso de } \\
\text { tierra }\end{array}$ \\
\hline & & & $\begin{array}{l}\text { Promedio de ocupantes } \\
\text { por cuarto }\end{array}$ \\
\hline & & \multirow[t]{2}{*}{ Bienes } & $\begin{array}{l}\% \text { Viviendas sin refrige- } \\
\text { rador }\end{array}$ \\
\hline & & & $\%$ Viviendas sin lavadora \\
\hline
\end{tabular}

Fuente: elaboración propia con base en Coneval (2007).

Cada uno de los indicadores fueron calculados con base en la metodología del Coneval (2007).

Por otra parte, para el cálculo del Índice de Gini se empleó la siguiente fórmula:

$$
I_{G}=\frac{\sum_{j<i}^{k}(x i-x j) p i p j}{\overline{l X}}
$$

Donde:

$X_{i}=\left\{X_{1}<X_{2}<\ldots<X_{k}\right\}: \mathrm{k}$ valores distintos que toma la variable estadística $X$ $p_{i}=\left\{p_{1}, p_{2} \ldots, p_{k}\right\}$ : frecuencias relativas $\left(p_{i}=n_{i} / N\right.$, con $N=\sum_{i=1}^{k} n_{i}$. Por tanto, $\sum_{i=1}^{k} x_{i} n_{i}$ resulta ser el total (masa salarial, renta, ...) asignada en el colectivo 
$n_{i}=\left\{n_{1}, n_{2} \ldots, n_{k}\right\}:$ frecuencias absolutas asociadas

$q i$ : masa relativa repartida entre los miembros de la clase i-ésima; es decir

$$
q i=\left(x_{i} n_{j} / \sum_{j=1}^{k}\left(x_{i} n_{j}\right)\right.
$$

$\bar{X}=$ Representa la media de la variable

Esta fórmula nos permite calcular la desigualdad de un valor en relación con todos los demás y de ahí obtener la desigualdad total del grupo de datos empleados. Para más detalles de la fórmula puede consultarse Ferreira y Garín (1997).

Para la comprobación de la hipótesis se utiliza el método de regresión lineal múltiple y será válida si la correlación manifiesta un valor mayor a 0.60 y que además posea una significancia $\geq 90 \%$. El valor obtenido en sentido positivo o negativo se evaluará con la escala: 0.00 a 0.20 (muy baja), 0.21 a 0.40 (baja), 0.41 a 0.60 (media), 0.61 a 0.80 (alta) y 0.81 a 1.00 (muy alta).

\section{Análisis de contexto}

En este apartado se realiza un análisis del contexto de las ciudades multiculturales consideradas para este artículo, retomando aspectos demográficos, sociales, económicos, así como los indicadores de desarrollo; entre ellos, el Índice de Marginación, el Índice de Desarrollo Humano y el Índice de Rezago Social a nivel municipal. Los datos marcados con colores azules indican las ciudades con las condiciones más favorables y los marcados con color rojo indican las ciudades con las condiciones desfavorables, según la información obtenida.

$\mathrm{Al}$ respecto, cabe advertir que desde la década de los noventa del siglo XX se considera que el Estado mexicano, en lugar de aminorar los grados de desigualdad, los ha fomentado para generar un desarrollo regional más desequilibrado y desarticulado (Merchand, 2014). El desarrollo regional en México se ha expresado históricamente en distorsiones territoriales que son producto de una excesiva concentración económica, centralidad de las decisiones políticas y desigual distribución de los beneficios. La ubicación geográfica del aparato productivo, la inequitativa distribución regional del ingreso y la calidad de vida de la población han favorecido al centro y el norte del país, quedando marginados el sur y el sureste (Delgadillo, 2008).

Este desarrollo se ha reflejado al interior de las ciudades y las grandes zonas metropolitanas caracterizadas por un crecimiento anárquico, que también manifiestan las desigualdades territoriales y la ausencia o deficiencia de la planeación espacial, que se plasman en elevados déficits de vivienda, 
infraestructura y servicios sociales para los sectores populares; segregación territorial por clases sociales y calidad de vida; agudo problema de transporte, congestión vehicular y pérdida de productividad y eficiencia por el tiempo de circulación humana y mercantil; crecientes índices de contaminación de la atmósfera, el suelo y el agua en su interior y la periferia (Pradilla, 1995). Las regiones y ciudades de Oaxaca no son ajenas a este proceso que tiene una duración de décadas, aunque posee sus propias peculiaridades.

Una de las condiciones que caracteriza al estado de Oaxaca es su riqueza multicultural, ya que su territorio alberga la mayor variedad de grupos originarios. En este estado conviven 16 grupos etnolingüísticos: amuzgos, chatino, chinanteco, chocho, chontal, cuicateco, huave, ixcateco, mazateco, mixe, mixteco, náhuatl, triqui, zapoteco, zoque y el popoloca en peligro de extinción (Berumen, 2003).

En cuanto a las ciudades en estudio, éstas albergan aproximadamente $22 \%$ del total de la población indígena del estado. Las lenguas que predominan en estas ciudades son el zapoteco, seguido del mixteco, el mixe, y sólo en Tuxtepec, el chinanteco. De acuerdo con la tabla 3, la ciudad que alberga el mayor número de población originaria es Juchitán con aproximadamente $85 \%$ del total de sus habitantes, seguida de Tlaxiaco e Ixtepec con un 46.90 y $43.50 \%$, respectivamente.

Tabla 3

Análisis de las características demográficas y sociales

\begin{tabular}{lcccccc}
\hline \multicolumn{1}{c}{ Ciudad } & \multicolumn{2}{c}{ Población } & Salud & \multicolumn{2}{c}{ Educación } & Vivienda \\
\hline & Total & $\begin{array}{c}\text { POBIND } \\
(\%)\end{array}$ & $\begin{array}{c}\text { POBSSS } \\
(\%)\end{array}$ & $\begin{array}{c}\text { POBANA } \\
(\%)\end{array}$ & PROESC & ICV \\
\hline IXT & 7674 & 75.02 & 38.94 & 10.71 & 7.2 & 0.58 \\
TEO & 8966 & 39.88 & 44.17 & 13.05 & 8.2 & 0.75 \\
CUI & 9441 & 28.31 & 21.85 & 13.06 & 6.4 & 0.56 \\
OCO & 21,341 & 8.38 & 42.41 & 10.44 & 7.6 & 0.44 \\
IXP & 26,450 & 43.50 & 27.00 & 9.7 & 8.5 & 0.76 \\
MRO & 38,019 & 27.25 & 46.11 & 12.63 & 7.1 & 0.77 \\
TLA & 38,453 & 46.90 & 62.43 & 10.36 & 8.4 & 0.48 \\
CRU & 38,629 & 8.95 & 29.35 & 10.7 & 9.8 & 0.86 \\
MIA & 41,387 & 18.08 & 57.11 & 15.9 & 6.5 & 0.42 \\
LOB & 41,535 & 6.97 & 34.82 & 14.41 & 6.3 & 0.85 \\
PES & 42,860 & 9.15 & 35.12 & 11.44 & 8.6 & 0.85 \\
PNA & 50,309 & 36.80 & 44.04 & 17.06 & 7.1 & 0.38 \\
\hline
\end{tabular}


Tabla 3 (continuación)

\begin{tabular}{lcccccc}
\hline \multicolumn{1}{c}{ Ciudad } & \multicolumn{2}{c}{ Población } & Salud & \multicolumn{2}{c}{ Educación } & Vivienda \\
\hline & Total & $\begin{array}{c}\text { POBIND } \\
\text { (\%) }\end{array}$ & $\begin{array}{c}\text { POBSSS } \\
(\%)\end{array}$ & $\begin{array}{c}\text { POBANA } \\
\text { (\%) }\end{array}$ & PROESC & ICV \\
\hline HUA & 69,839 & 13.49 & 43.47 & 7.53 & 8.6 & 0.75 \\
JUC & 93,038 & 85.68 & 44.17 & 14.25 & 7.7 & 0.79 \\
TUX & 155,766 & 30.58 & 34.90 & 9.01 & 8.1 & 0.81 \\
ZMT & 161,337 & 25.32 & 34.47 & 9.7 & 7.3 & 0.77 \\
ZMO & 607,963 & 20.04 & 38.92 & 4.9 & 9.4 & 0.74 \\
\hline
\end{tabular}

POBIND=Población indígena, POBSSS=Población sin servicios de salud, POBANA= Población Analfabeta, PROESC=Promedio de escolaridad, ISV= Índice de servicios en la vivienda.

Fuente: elaboración propia con base en los datos de INPI (2016) e Inegi (2010).

Con respecto al acceso a la salud pública, las ciudades con mayor porcentaje de población sin servicio de salud son Tlaxiaco y Miahuatlán, ya que superan $50 \%$ sin acceso a este servicio; por el contrario, las ciudades que presentan la mejor situación son Ixtepec, Crucecita y Cuicatlán. El panorama del resto de las ciudades no es nada motivador, ya que la mayoría supera la tercera parte de su población sin acceso a este servicio.

En lo que corresponde al aspecto educativo, las ciudades que tienen mayor población analfabeta son Pinotepa Nacional, Miahuatlán y Loma Bonita. Por otra parte, en el indicador de años promedio de escolaridad vuelven a coincidir esas ciudades a excepción de Pinotepa, lo cual demuestra que se están quedando rezagadas en cuanto a la dimensión educativa. Es importante resaltar que todas las ciudades, con excepción de Pinotepa Nacional, se encuentran por debajo del promedio estatal (16.9\%) de población analfabeta. En cuanto al otro indicador, hay tres ciudades: Loma Bonita, Miahuatlán y Cuicatlán, que están por debajo del promedio estatal (6.9) en años promedio de escolaridad.

Otro aspecto fue el acceso a los servicios en las viviendas, por medio de un índice que incluyó el acceso a drenaje, agua, luz eléctrica, hacinamiento, piso de tierra y servicio sanitario (ISV). Las ciudades que presentaron las mejores condiciones en sus viviendas fueron Crucecita, Puerto Escondido, Loma Bonita y Tuxtepec, ya que presentaron un índice arriba de 0.80 , considerando que la mejor situación es 1 . En cuanto a las zonas metropolitanas se puede observar que presentan un índice menor al 0.80 , lo que indica que muestran todavía una gran carencia de servicios y condiciones básicas en las viviendas. La situación más desfavorable se vive en Pinotepa Nacional, ciudad seguida por Miahuatlán y Ocotlán, lo que indica una muy baja dotación de los servicios básicos en las viviendas ubicadas en estas ciudades. 
El aspecto económico también es un elemento muy importante, sobre todo en el desarrollo de las ciudades, ya que éstas se consideran los motores económicos de la sociedad. Por ello, en la tabla 4 se presentan los principales indicadores económicos del grupo de ciudades analizadas.

Tabla 4

Análisis de indicadores económicos, 2010

\begin{tabular}{lccl}
\hline \multicolumn{1}{c}{ Ciudad } & \multicolumn{3}{c}{ Indicadores económicos } \\
\hline CUI & PIB & INGRESO & GINI \\
\hline IXT & 6877.85 & 0.699 & 0.45 \\
MIA & 7939.19 & 0.730 & 0.45 \\
PNA & 8340.65 & 0.738 & 0.48 \\
PES & 8363.04 & 0.739 & 0.39 \\
JUC & 9409.31 & 0.758 & 0.43 \\
TEO & 9676.25 & 0.763 & 0.43 \\
ZMT & $10,309.80$ & 0.760 & 0.43 \\
MRO & $11,072.38$ & 0.786 & 0.48 \\
OCO & $11,297.75$ & 0.789 & 0.47 \\
LOB & $11,550.24$ & 0.793 & 0.42 \\
CRU & $12,787.35$ & 0.810 & 0.45 \\
ZMO & $14,073.47$ & 0.823 & 0.44 \\
TUX & $14,383.27$ & 0.829 & 0.44 \\
IXP & $15,878.89$ & 0.846 & 0.44 \\
TLA & $16,025.73$ & 0.847 & 0.42 \\
HUA & $20,387.32$ & 0.888 & 0.44 \\
\hline & & 5896 & 0.45 \\
\hline
\end{tabular}

Fuente: elaboración propia con base en los datos del PNUD (2014) y Coneval (2011).

De acuerdo con los datos del Producto Interno Bruto per cápita (PIB), la ciudad que contó con un mayor PIB en el 2010 fue Huajuapan, con un valor de 20,387.3 dólares, mientras la ciudad con un menor PIB fue Cuicatlán, seguida de Ixtlán y Miahuatlán.

Para el análisis del ingreso, se tomó el índice de ingreso que utilizó el Programa de las Naciones Unidas para el Desarrollo (PNUD), los resultados obtenidos mostraron que la ciudad con un mayor ingreso, de acuerdo con el índice calculado, fue Huajuapan (0.89), seguido de Tlaxiaco (0.847) e Ixtepec (0.846). La ZMO también representó una de las zonas con 
mayor nivel de ingreso, ya que presentó un índice de (0.82). La ciudad que manifestó un menor ingreso en este indicador fue Cuicatlán (0.669).

Como último indicador evaluado de este aspecto se tomó en cuenta el Índice de Gini que mide la desigualdad económica de una sociedad, mediante la exploración del nivel de concentración que existe en la distribución de los ingresos entre la población. El coeficiente de Gini toma valores entre cero y uno; un valor que tiende a uno refleja mayor desigualdad en la distribución del ingreso. Los datos mostraron que las ciudades con una mayor desigualdad económica para el 2010 fueron Pinotepa Nacional, Matías Romero y Ocotlán. Sin embargo, todas las ciudades a excepción de Puerto Escondido, presentaron un índice arriba de 0.40 , lo

Tabla 5

Análisis de indicadores de desarrollo, 2010

\begin{tabular}{|c|c|c|c|}
\hline \multirow[t]{2}{*}{ Ciudad } & \multicolumn{2}{|c|}{ Grados que predominan } & Indice de Desarrollo Humano \\
\hline & Marginación & Rezago Social & Valor del Índice \\
\hline HUA & Alto, Medio & Bajo, Medio & 0.8752 \\
\hline ZMO & Alto, Medio & Bajo, Medio & 0.8675 \\
\hline TLA & Muy Alto, Alto & Medio & 0.8615 \\
\hline TUX & Alto, Medio & Bajo, Medio & 0.8607 \\
\hline IXP & Medio & Bajo & 0.8560 \\
\hline CRU & Medio & Bajo & 0.8469 \\
\hline TEO & Muy Alto, Alto & Bajo, Medio & 0.8404 \\
\hline MRO & Alto, Medio & Bajo, Medio & 0.8354 \\
\hline LOB & Alto, Medio & Bajo & 0.8330 \\
\hline OCO & Muy Alto, Alto & Medio, Alto & 0.8320 \\
\hline JUC & Alto, Medio & Bajo, Medio & 0.8295 \\
\hline PES & Alto, Medio & Medio, Bajo & 0.8206 \\
\hline ZMT & Alto, Medio & Bajo, Medio & 0.8157 \\
\hline IXT & Medio & Bajo & 0.8138 \\
\hline PNA & Muy Alto, Alto & Medio, Alto & 0.8023 \\
\hline MIA & Muy Alto, Alto & Medio, Alto & 0.7946 \\
\hline CUI & Muy Alto, Alto & Bajo, Medio & 0.7857 \\
\hline
\end{tabular}

Fuente: elaboración propia con base en los datos del PNUD (2014), Conapo (2012) y Cone$\operatorname{val}(2010)$. 
que señala que las ciudades del estado de Oaxaca se podrían considerar con una desigualdad catalogada como media.

Para el último grupo de indicadores evaluados se tomaron en cuenta los indicadores relacionados con el nivel de desarrollo. Como se observa en la tabla 5, varias ciudades que tienen condiciones desfavorables en un aspecto también presentan condiciones desfavorables en otros; por ejemplo, las ciudades caracterizadas por los altos grados de marginación coindicen también con la variable de ser las más rezagadas. En este análisis, con la aplicación de los índices mencionados, es posible ubicar a Miahuatlán como la ciudad con las condiciones más desfavorables de todo el grupo, ya que predominan los niveles altos, tanto de marginación como de rezago social en el nivel AGEB, y es también una de las ciudades con un menor nivel de desarrollo. Además, se observa que en relación con el índice de marginación urbana en la mayoría de las ciudades predominan los niveles altos de marginación.

En cuanto al Índice de Desarrollo Humano, las ciudades que presentaron las mejores condiciones fueron las pertenecientes a la región mixteca, la cual se caracteriza por los altos niveles de migración, y por consecuencia, una de las regiones que mayor cantidad de remesas recibe. También entre éstas se encuentra la Zona Metropolitana de Oaxaca, considerada la zona más importante del estado.

De manera general, derivado de este análisis de contexto, se puede concluir que la ciudad con las condiciones más desfavorables fue Miahuatlán. Esto con base en que fue la ciudad con el mayor porcentaje de población no afiliada a servicios de salud, con el mayor porcentaje en analfabetismo, con una población con menor nivel académico y con una gran carencia de servicios básicos en sus viviendas. Además, fue una de las ciudades con menor PIB, manifestó alto grado, tanto de rezago social como de marginación, y presentó un IDH menor al resto de las ciudades. Por el contrario, la ciudad que presentó mejores condiciones para su desarrollo fue la Crucecita (Huatulco), ya que presentó buenas condiciones en cuanto a salud, educación, servicios básicos en sus viviendas y menores niveles de marginación y rezago social.

\section{Resultados}

Para la presentación de los resultados se clasificaron las ciudades de acuerdo con su tamaño poblacional, estructurados de la siguiente manera: pequeñas ciudades (con una población menor a los 15,000 habitantes), ciudades medias (de 15,000 a 50,000 habitantes), grandes ciudades (mayores a los 50,000 habitantes) y las zonas metropolitanas. 
Por otra parte, en cuanto al Índice de Gini, éste comprende valores entre el cero y el uno, cuanto más cercano se encuentra de la unidad mayor es el nivel de desigualdad y mientras más cercano se encuentre del cero indica una mayor igualdad. De acuerdo con lo anterior y para una mejor interpretación en este artículo se propone la siguiente clasificación (tabla 6):

Tabla 6

Valores de interpretación del Índice de Gini

\begin{tabular}{ll}
\hline \multicolumn{1}{c}{ Intervalo } & \multicolumn{1}{c}{ Interpretación } \\
\hline Valores entre 0-0.30 & Distribución equitativa \\
Valores entre 0.31-60 & $\begin{array}{l}\text { Se puede hablar de situaciones de desigualdad/presen- } \\
\text { cia de desigualdad }\end{array}$ \\
Valores superiores a.60 & Distribución gravemente inequitativa \\
\hline
\end{tabular}

Fuente: elaboración propia con base en información documental.

Los resultados obtenidos para cada una de las ciudades se muestran en la tabla 7 :

Tabla 7

\section{Índice de Gini para las ciudades de Oaxaca}

\begin{tabular}{llcl}
\hline \multicolumn{3}{c}{ Ciudad } & \multicolumn{3}{c}{ Coeficiente de Gini } \\
& 1990 & 2000 & 2010 \\
\hline $\boldsymbol{L O B}$ & 0.39 & 0.31 & 0.39 \\
$\boldsymbol{C R U}$ & 0.50 & 0.42 & 0.30 \\
$\boldsymbol{C U I}$ & 0.16 & 0.25 & 0.34 \\
$\boldsymbol{H U A}$ & 0.45 & 0.22 & 0.51 \\
$\boldsymbol{I X P}$ & 0.47 & 0.35 & 0.45 \\
$\boldsymbol{I X T}$ & 0 & 0.39 & 0.50 \\
$\boldsymbol{J U C}$ & 0.43 & 0.24 & 0.19 \\
$\boldsymbol{M R O}$ & 0.38 & 0.48 & 0.18 \\
$\boldsymbol{M I A}$ & 0.15 & 0.32 & 0.53 \\
$\boldsymbol{O C O}$ & 0.44 & 0.30 & 0.45 \\
$\boldsymbol{P N A}$ & 0.45 & 0.23 & 0.36 \\
$\boldsymbol{P E S}$ & 0.23 & 0.33 & 0.49 \\
\hline
\end{tabular}


Tabla 7 (continuación)

\begin{tabular}{lccc}
\hline Ciudad & \multicolumn{3}{c}{ Coeficiente de Gini } \\
& 1990 & 2000 & 2010 \\
\hline $\boldsymbol{T E O}$ & 0.11 & 0.51 & 0.68 \\
$\boldsymbol{T L A}$ & 0.30 & 0.22 & 0.19 \\
$\boldsymbol{T U X}$ & 0.27 & 0.32 & 0.44 \\
$\boldsymbol{Z M O}$ & 0.27 & 0.25 & 0.47 \\
$Z \boldsymbol{Z M T}$ & 0.19 & 0.24 & 0.22 \\
\hline
\end{tabular}

Fuente: elaboración propia.

Los resultados obtenidos y su evolución en cada una de las ciudades se observan en el mapa 2.

\section{Mapa 2 \\ Índice de Gini para las ciudades del estado de Oaxaca, periodo 1990-2010}
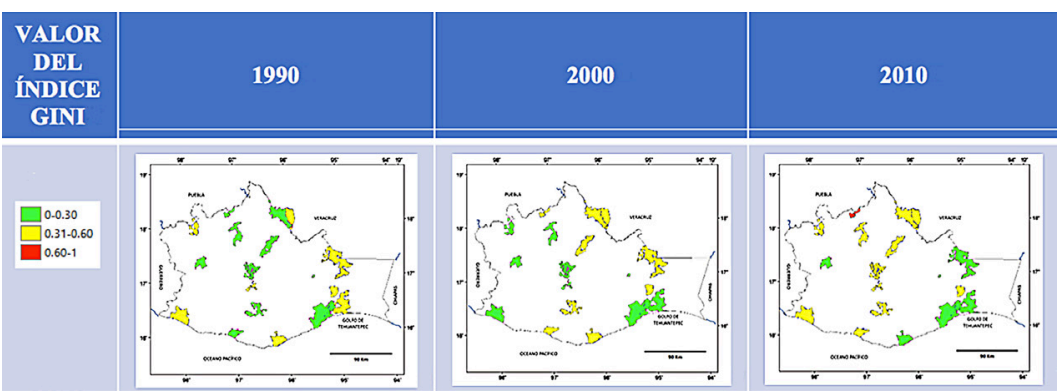

Fuente: elaboración propia con apoyo del software Mapa Digital Versión 6.1.0 (Inegi, 2013).

\subsection{Pequeñas ciudades}

En este grupo de ciudades se puede observar un incremento constante de la desigualdad, sobre todo en el caso de Teotitlán e Ixtlán; por su parte, Cuicatlán presenta un aumento con menos intensidad (gráfica 1). 


\section{Gráfica 1}

\section{Comportamiento del Índice de Gini en las pequeñas ciudades}

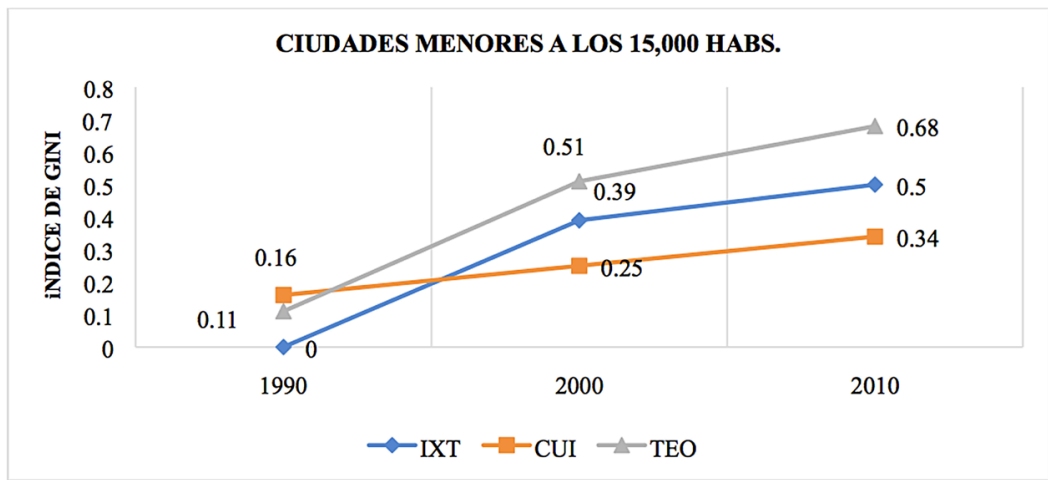

Fuente: elaboración propia.

\subsection{Medianas ciudades}

De este grupo, se observa que en la mayoría de las ciudades la desigualdad tiende a aumentar con el paso del tiempo (gráfica 2), siendo Miahuatlán la ciudad con el Índice de Gini más alto. Se observan tres ciudades con un comportamiento diferente: Crucecita, Matías Romero y Tlaxiaco,

\section{Gráfica 2}

\section{Comportamiento del Índice de Gini en las medianas ciudades}

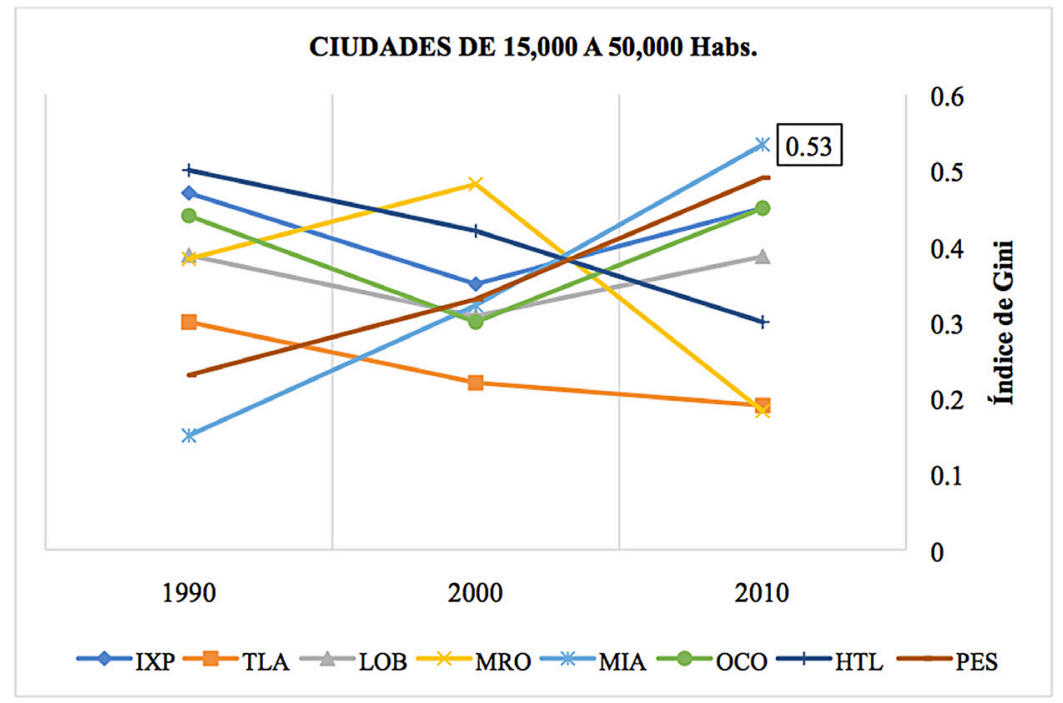

Fuente: elaboración propia. 
en las que la desigualdad tiende a disminuir. Crucecita, principalmente, por la gran cantidad de recursos invertidos y Tlaxiaco probablemente a las remesas recibidas que permiten mejorar la calidad de vida.

\subsection{Grandes ciudades}

Con respecto a las ciudades con más de 50,000 habitantes, el caso que resalta es la ciudad de Juchitán debido a que su nivel de desigualdad decrece en el periodo observado (gráfica 3). De un valor de Índice de Gini de 0.43 en 1990 bajó a un valor de 0.19 para el 2010. Las demás ciudades como Huajuapan y Pinotepa presentan un declive de su desigualdad en el 2000, pero para el 2010 vuelve a aumentar. Por su parte, Tuxtepec es la única ciudad de este grupo que mantiene un incremento de su desigualdad de manera constante.

\section{Gráfica 3}

\section{Comportamiento del Índice de Gini en las grandes ciudades}

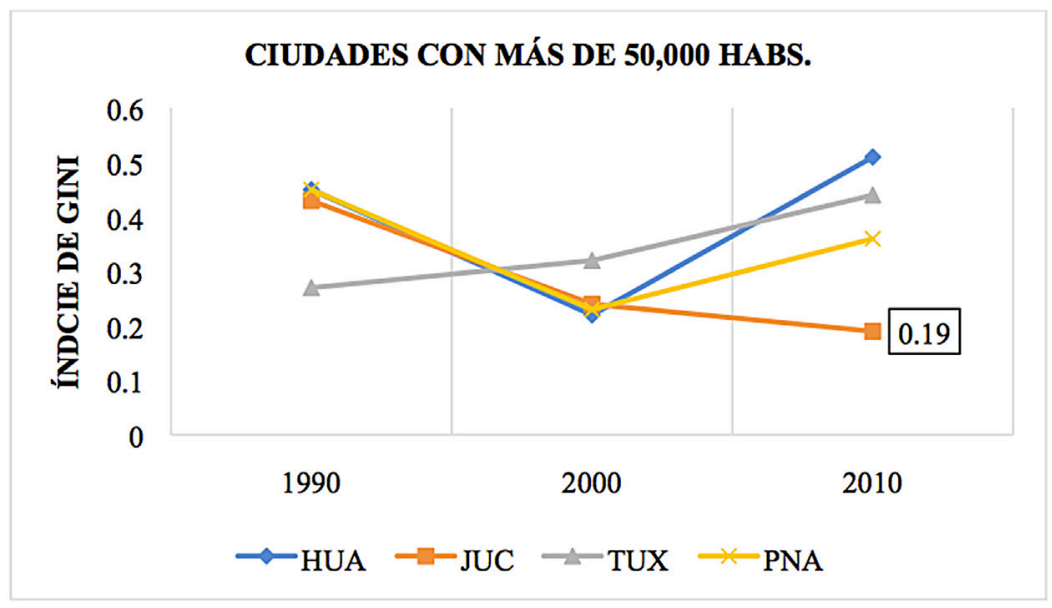

Fuente: elaboración propia.

\subsection{Zonas metropolitanas}

Ambas zonas metropolitanas muestran un crecimiento de la desigualdad al interior de ellas (gráfica 4); sin embargo, la Zona Metropolitana de Oaxaca es la que presenta un mayor crecimiento.

Se puede confirmar con los resultados obtenidos que en el periodo analizado la desigualdad intraurbana en las ciudades del estado de Oaxaca 
Gráfica 4

Comportamiento del Índice de Gini en las zonas metropolitanas

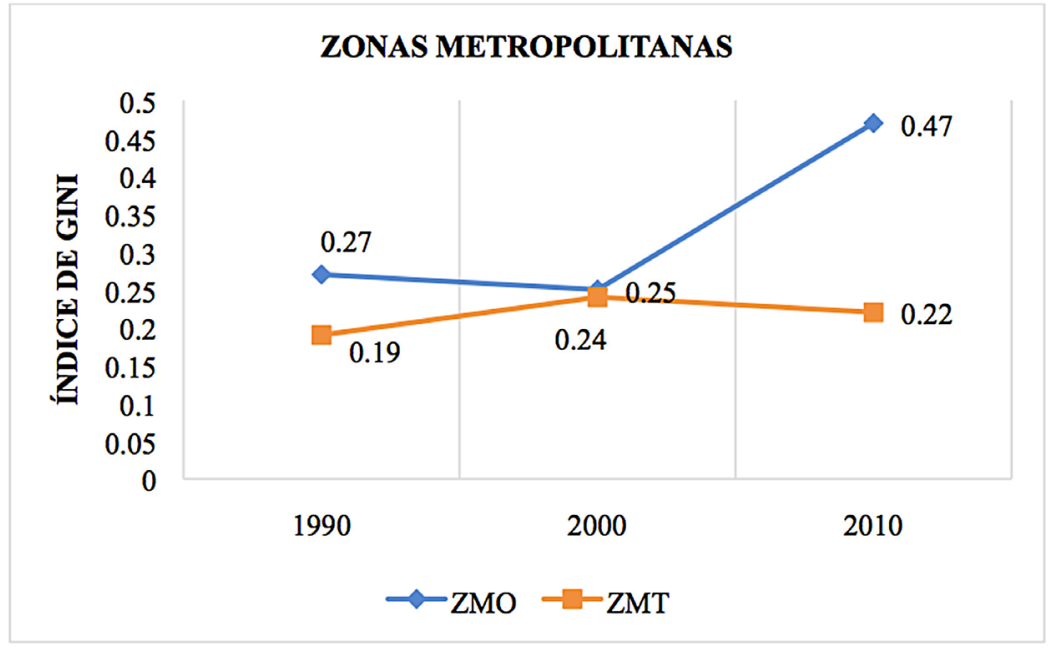

Fuente: elaboración propia.

está aumentando. En la gráfica 5 se muestran las tasas de crecimiento calculadas por periodo y por estrato urbano. Se observa que de manera general la desigualdad va en aumento en las ciudades analizadas, donde son las pequeñas ciudades las que tienen las mayores tasas de crecimiento, siendo el periodo del 2000 al 2010 donde la desigualdad aumenta en todos los estratos.

\section{Gráfica 5}

\section{Tasa de crecimiento del Gini por periodo y estrato de ciudad}

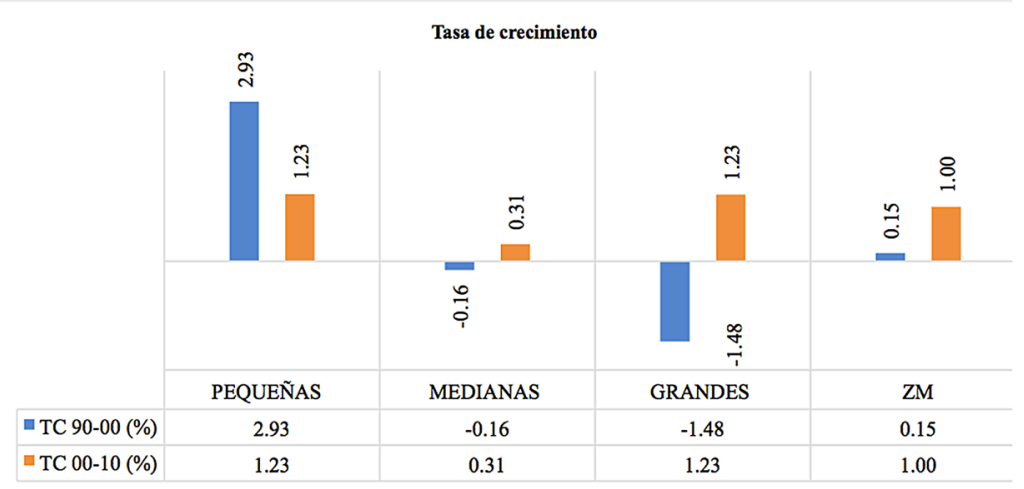

Fuente: elaboración propia. 


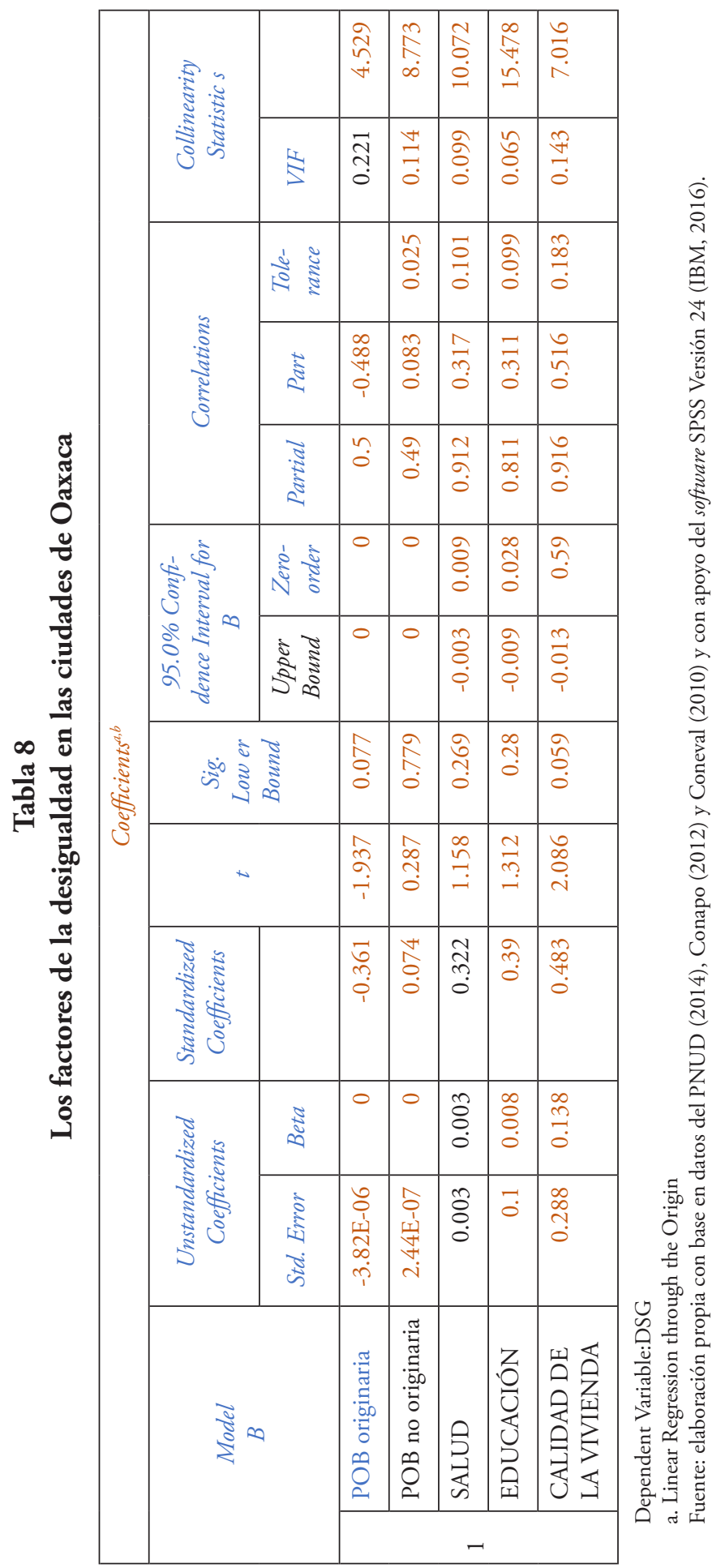




\subsection{Los factores de la desigualdad}

Tomando en cuenta los indicadores considerados en el presente artículo, y después de realizar el análisis de regresión múltiple respectivo, en la tabla 8 se observa que el mayor peso estadístico con respecto a las desigualdades territoriales de las ciudades se posiciona sobre la calidad de la vivienda (beta: 0.483), el nivel educativo (beta: 0.390) y la cantidad de población originaria (beta: -0.361), con la consideración de que en el caso de las ciudades analizadas, a mayor población originaria existente en las mismas, menores son las desigualdades intraurbanas que manifiestan, por lo que la hipótesis planteada originalmente, que esperaba que el mayor peso estadístico lo manifestara la cantidad de población originaria comparada con los indicadores del Índice de Rezago Social, se rechaza.

\section{Discusión y conclusiones}

El cálculo del Índice de Rezago Social ayudó a identificar cuáles son las zonas de las ciudades con las mayores carencias sociales. A través del valor cuantitativo de dicho índice fue posible la aplicación del Índice de Gini. Este procedimiento ayudó a medir las diferencias existentes entre las AGEB de las localidades y permitió conocer el nivel de desigualdad al interior de las ciudades, así como concluir que la hipótesis del artículo que proponía que las desigualdades estuvieran fuertemente asociadas a la cantidad de población originaria existentes en las mismas se rechace, pues en las ciudades oaxaqueñas sucede lo contrario: entre menos población originaria posea una ciudad, mayor es la desigualdad interna que manifiestan.

Una reflexión inmediata de este resultado remite a concluir que en las ciudades analizadas no puede descartarse que la multiculturalidad influye en la desigualdad, sobre todo en las decisiones de asignación de los recursos públicos para combatirla, sujetas a los usos y costumbres de las comunidades urbanas oaxaqueñas que influyen en que las periferias de las ciudades queden marginadas de dicha asignación por contar con población denominada avecindada, es decir, no originaria de la ciudad; pero que existen otros factores no valorados en el presente artículo que también generan efectos en la desigualdad urbana, como los comentados por Soja (2009), 1) la discriminación en sus tres formas conocidas: étnica, de género y de clase; 2) las políticas y acciones gubernamentales que reorientan las inversiones urbanas, institucionalizan la segregación residencial, crean estructuras centro-periferia y zonifican el territorio injustamente; 3) el funcionamiento cotidiano del sistema urbano que responde a los incentivos y las decisiones de localización del capital, es decir, que en la medida 
que el funcionamiento de la ciudad opere a favor de las clases adineradas y empresariales, bien para concentrarse o para ocupar zonas antes habitadas por clases populares, la redistribución de los beneficios y los ingresos reales tenderán a desplazarse con el capital, y 4) la conformación de estructuras geográficas diferenciadas por los grados de desarrollo social, económico e institucional, así como por los privilegios intactos que no se regulan para provecho colectivo de la ciudad o región metropolitana.

Lo que también es común en las mismas son las insuficiencias en las capacidades técnicas, administrativas y organizativas que los gobiernos municipales muestran como problema de raíz, que impide una mejor eficacia en su gestión (Martínez, 2019). Como resultado, el crecimiento de las ciudades se está dando en forma desordenada, sin ningún tipo de lineamiento que guíe este crecimiento, dejando a diversas zonas de las mismas con muchas carencias. Esta falta de interés en la implementación de un orden y mejoramiento de las condiciones de vida de la población, sobre todo de los más vulnerables, hacen que cada ciudad se desarrolle de una forma muy heterogénea y que presenten grandes desigualdades en su interior.

Pero también, con base en el análisis realizado, se observa que cada ciudad del estado de Oaxaca presenta una dinámica diferente, pues como lo mencionan Vélez y Mejía, las "experiencias urbanas son diversas y obedecen a aspectos de ubicación de quienes las habitan y cómo interactúan entre sí, la forma en que se produce el espacio urbano, su forma de organización, así como esquemas de apropiación y uso de este" (2016: 96). Por lo que, adicionalmente a las reflexiones anteriores, se comenta que las ciudades con mayor desigualdad como Teotitlán e Ixtlán -ciudades catalogadas como pequeñas-, Miahuatlán -de las ciudades medianas-, Huajuapan -de las grandes ciudades- y la ZMO en las zonas metropolitanas, muestran que la desigualdad se asocia más a las ciudades que poseen una menor población originaria. Las ciudades pequeñas (Teotitlán, Ixtlán, Cuicatlán) están caracterizadas por tener una actividad económica baja, es decir, las oportunidades de un empleo formal son escasas, además de que también predominan las actividades primarias y son altamente dependientes de los recursos federales. Estas características les impiden tener un ingreso suficiente para mejorar sus condiciones y que se vea reflejado en sus niveles de desigualdad. A su vez, también tienen una dotación de infraestructura de salud y educación escasa.

Existe una ciudad con mejor situación económica: la Crucecita, Huatulco, que al ser un Centro Integral Planeado (CIP), su desarrollo se deriva de grandes inversiones. Pero, detrás de todo ese desarrollo hubo también un proceso de despojo y exclusión de la población originaria. Por ello, aunque la desigualdad intraurbana de la ciudad es baja, la desigualdad económica que presenta es mucho mayor. Es decir, los beneficios 
económicos que la actividad turística está generando no se han distribuido de una manera adecuada. Una situación similar se presenta en la Zona Metropolitana de Oaxaca, ya que, a pesar de ser la ciudad con mayores oportunidades de empleo, educación y acceso a salud es también una de las más desiguales. Esto se debe a su rápido crecimiento que ha hecho más difícil implementar mecanismos de ordenamiento territorial y suministro de servicios básicos. Además, debido a su crecimiento poblacional, las oportunidades de acceso a la educación y salud se ven cada vez más limitadas.

En resumen, el análisis retrospectivo realizado aporta la consideración que el proceso de desarrollo aún vigente en las ciudades analizadas no ha sido resuelto y está incrementando su nivel de desigualdades preferentemente en las ciudades que poseen una menor población originaria, y que el problema de la desigualdad en estas ciudades es multifactorial.

\section{Fuentes de consulta}

Arias Goytre, Félix (2005), "El estudio de la desigualdad urbana", Urbano, 8 (11), Concepción, Universidad de Bío Bío, pp-77-83.

Ayala Ramírez, Carlos (2012), "Desigualdad territorial”, Agencia Latinoamericana de Información-ALAI, [Weblog], 9 de julio de 2012, $<$ https://www.alainet.org/es/active/56380>, 15 de enero de 2018.

Benita Maldonado, Francisco y Gómez Meza, Marco Vinicio (2013), “El rezago social en áreas metropolitanas de México”, Estudios Económicos, 8 (2), Ciudad de México, El Colegio de México, pp. 265-297.

Berumen Barbosa, Miguel Enrique (2003), "Geografía Económica de Oaxaca”, eumed.net, Málaga, Universidad de Málaga, <https://www. eumed.net/cursecon/libreria/mebb/>, 16 marzo de 2018.

Conapo (Consejo Nacional de Población) (2012), "Índice de marginación urbana 2010”, Ciudad de México, Conapo.

Coneval (Consejo Nacional de Evaluación de la Política de Desarrollo Social) (2011), "Medición de la pobreza, Estados Unidos Mexicanos, 2010. Indicadores de Cohesión social por municipio", Ciudad de México, Coneval, <https://www.coneval.org.mx/Medicion/MP/Paginas/Anexo-estad\%C3\%ADstico-municipal-2010. aspx>, 25 de junio de 2017. 
Coneval (Consejo Nacional de Evaluación de la Política de Desarrollo Social) (2010), "Rezago Social a Nivel Zonas Urbanas. Nota técnica del cálculo del Rezago Social en las AGEB urbanas de México”, Ciudad de México, Coneval.

Coneval (Consejo Nacional de Evaluación de la Politica de Desarrollo Social) (2007), "Los mapas de pobreza en México: Anexo técnico metodológico", Ciudad de México, Coneval.

Delgadillo Macías, Javier (2008), "Desigualdades territoriales en México derivadas del tratado de libre comercio de América del Norte", Revista EURE, 34 (101), Santiago de Chile, Pontificia Universidad Católica de Chile, pp. 71-98, doi: http://dx.doi.org/10.4067/ S0250-71612008000100004

DOF (Diario Oficial de la Federación) (2010), "Lineamientos y criterios generales para la definición, identificación y medición de la pobreza", Ciudad de México, Segob, 16 de junio, <http://dof. gob.mx/nota_detalle.php?codigo $=5146940 \& \mathrm{fe}$ cha $=16 / 06 / 2010>, 20$ de mayo del 2017.

DOF (Diario Oficial de la Federación) (2004), "Ley General de Desarrollo Social", Ciudad de México, Secretaría de Desarrollo Social, 20 de enero, <http://www.diputados.gob.mx/LeyesBiblio/ref/ lgds/LGDS_orig_20ene04.pdf> 20 de mayo del 2017.

Fernández-García, Manuel; Navarro Yáñez, Clemente; Zapata Moya, Ángel y Mateos Mora, Cristina (2018), "El análisis de la desigualdad urbana, propuesta y validación de un índice de nivel socioeconómico en áreas urbanas españolas (1991-2001)”, EMPIRIA: Revista de Metodología de Ciencias Sociales, núm. 39, Madrid, Universidad Nacional de Educación a Distancia, pp. 49-77, doi: https://doi.org/10.5944/empiria.39.2018.20877

Ferreira García, Eva y Garín Martín, María Araceli (1997), “Una nota sobre el cálculo del índice Gini”, Estadística Española, 39 (142), Madrid, Instituto Nacional de Estadística, pp. 207-218.

George, Pierre (1983), Geografía de las desigualdades, Barcelona, Oikos-tau.

Harvey, David (1973), Urbanismo y desigualdad social, Madrid, Siglo XXI Editores. 
IBM (International Business Machines Corporation) (2016), "SPSS Statistics", [software], Versión 24, Nueva York, International Business Machines Corporation.

Inegi (Instituto Nacional de Estadística y Geografía) (2013), “Mapa Digital de México", [software], Versión 6.1.0, Aguascalientes, Instituto Nacional de Estadística y Geografía.

Inegi (Instituto Nacional de Estadística y Geografía) (2010), “Censo de Población y Vivienda, 2010. Tabulados Básicos. Población total por municipio, sexo y grupos quinquenales de edad según tamaño de localidad", Aguascalientes, Inegi, <https://www.inegi.org.mx/ programas/ccpv/2010/default.html\#Tabulados> , 27 de septiembre del 2016.

INPI (Instituto Nacional de los Pueblos Indígenas) (2016), "Cédulas de información básica de los municipios de México", Ciudad de México, Instituto Nacional de los Pueblos Indígenas, <http:// www.cdi.gob.mx/cedulas/>, 20 de octubre de 2016.

Insulza, José Miguel (2011), "Desigualdad, democracia e inclusion social”, Desigualdad e inclusión social en las Américas, 15 (11), Washington, D. C., Organización de los Estados Americanos, pp. 13-34.

Martínez Olivera, Christian (2019), "La gestión pública y el desarrollo local sustentable de las ciudades de Oaxaca, 2000-2017”, tesis de maestría, Instituto Tecnológico de Oaxaca, México.

Merchand Rojas, Marco Antonio (2014), “¿Es México un estado reproductor de las desigualdades regionales?”, Revista Finanzas y Politica Económica, 6 (2), Bogotá, Universidad Católica de Colombia, pp. 403-426, doi: http//dx.doi.org/10.14718/revfinanzpolitecon.2014.6.2.9

Miguel-Velasco, Andrés Enrique; Torres Valdez, Julio César; Hernández Vargas, Libia y Moncada García, Ma. del Rosario (2016). "El desarrollo sustentable y la centralidad de las localidades en una microrregión de pueblos originarios. El caso de la Sierra Sur de Oaxaca, México", Revista DELOS: Desarrollo Local Sostenible, 9 (25), Málaga, Universidad de Málaga, <http://www.eumed.net/ rev/delos/25/centralidad.html>, 28 de septiembre de 2019. 
Moreno Avendaño, Julita (2019), "Desigualdades inter e intraurbanas y desarrollo sustentable en las pequeñas, medianas y grandes ciudades de Oaxaca, 1990-2010", tesis de doctorado, Instituto Tecnológico de Oaxaca, México.

Pamplona, Francisco (2005), "Las desigualdades territoriales: el caso de la marginación”, Revista Economía Informa, (334), Ciudad de México, Universidad Autónoma de la Ciudad de México, pp. 22-35, <http://www.economia.unam.mx/publicaciones/reseconinforma/pdfs/334/04FranciscoPamplona.pdf>, 28 de septiembre de 2019.

Peppino Barale, Ana María (2004), "Desigualdad económica: definición, indices e indicadores", Casa del tiempo, 6 (70), Ciudad de México, Universidad Autónoma Metropolitana, pp. 2-11, <http://www. uam.mx/difusion/revista/nov2004/peppino.pdf>, 18 de agosto de 2018.

Pérez Pérez, Maribel (2018), "Factores socioeconómicos que inciden en el desempeño académico de los alumnos del nivel medio superior en las ciudades de Oaxaca 2000-2015”, tesis de doctorado, Instituto Tecnológico de Oaxaca, Oaxaca.

PNUD México (Programa de las Naciones Unidas para el Desarrollo) (2014), "Índice de Desarrollo Humano Municipal. Base de datos", Ciudad de México, PNUD, <http://www.mx.undp.org/content/ mexico/es/home/library/poverty/idh-municipal-en-mexico-nueva-metodologia.html>, 15 de octubre de 2017.

Pradilla Cobos, Emilio (1995), "La política territorial y la configuración urbano-regional”, en José Luis Calva y Adrián Guillermo Aguilar (coords.), Desarrollo regional y urbano, Ciudad de México, Juan Pablos Editores/Universidad Nacional Autónoma de México, pp. 131-151.

Puyana, Alicia (2018), "Desigualdad horizontal y discriminación étnica en cuatro países latinoamericanos", Revista de la CEPAL, núm. 125, Santiago de Chile, Comisión Económica para América Latina y el Caribe, pp. 47-70.

Reygadas, Luis (2008), “Tres matrices generadoras de desigualdades”, en Rolando Cordera, Patricia Ramírez, Alicia Ziccardi y Leonardo Lomelí Vanegas (coords.), Pobreza, desigualdad y exclusion social 
en la ciudad del siglo XXI, Ciudad de México, Siglo XXI Editores, pp. 92-114.

Sabatini, Francisco; Cáceres, Gonzalo y Cerda, Jorge (2001), "Segregación residencial en las principales ciudades chilenas: Tendencias de las tres últimas décadas y posibles cursos de acción", Revista EURE, 27 (82), Santiago de Chile, Universidad Católica de Chile, pp. 21-42.

Singer Sochet, Martha (2014), “¿Exclusión o inclusión indígena?”, Estudios politicos, núm. 31, Ciudad de México, Universidad Nacional Autónoma de Mexico, pp. 87-106.

Soja, Edward (2009), “The city and spatial justice”, Justice Spatiale/Spatial Justice, núm. 1, París, University Paris Nanterre's, Commission for Research-the UMR LAVUE (UMR 7218)- the Mosaïque group, the CNRS-the research group CUBES (University of Witwatersrand, South Africa)-the Urban Futures Labex (University Paris-Est), pp. 1-5, <https://www.jssj.org/article/la-ville-etla-justice-spatiale/>, 8 mayo de 2020.

Vélez Dávila, María Isabel Graciela y Mejía González, Ludivina (2016), "Los espacios urbanos como expresión de la desigualdad", PERSPECTIVAS: Revista de Análisis de Economía, Comercio y Negocios Internacionales, 10 (1), San Luis Potosí, Universidad Autónoma de San Luis Potosí, pp. 95-107.

Villegas, Claudia (2016), "De las ciudades multiculturales a las ciudades de inconformes. Algunas reflexiones sobre la protesta urbana en el siglo XXI”, Bifurcaciones, núm. 21, Talca, Universidad Cátolica de Maule <http://www.bifurcaciones.cl/2016/09/de-las-ciudades-multiculturales-a-las-ciudades-de-inconformes/>, 20 de mayo de 2019.

Recibido: 12 de noviembre de 2019. Reenviado: 4 de mayo de 2020. Aceptado: 7 de julio de 2020.

Julita Moreno Avendaño. Doctora en Ciencias en Desarrollo Regional y Tecnológico por el Instituto Tecnológico de Oaxaca, México. Su línea de investigación actual es desarrollo regional sustentable. Entre sus más recientes publicaciones como coautora están: "Educación media superior 
y desarrollo sustentable en las ciudades del estado de Oaxaca, México", Perfiles Educativos, 41 (163), Ciudad de México, Instituto de Investigaciones sobre la Universidad y la Educación, UNAM, pp. 69-87 (2019); "Análisis del impacto de las pequeñas y medianas ciudades en el cambio climático. El caso de Oaxaca, México 2000-2015”, Sociedad y Ambiente, 5 (14), San Cristóbal de las Casas, El Colegio de la Frontera Sur (Ecosur), pp. 99-118 (2017) y "El problema de la vivienda en las pequeñas, medianas y grandes ciudades de Oaxaca, México, 2000-2015”, Quivera, 19 (1), Toluca, Universidad Autónoma del Estado de México, pp. 61-84 (2017).

Andrés Enrique Miguel-Velasco. Doctor en Ciencias en Planificación de Empresas y Desarrollo Regional por el Instituto Tecnológico de Oaxaca, México. Actualmente es profesor-investigador de la División de Estudios de Posgrado e Investigación en el Instituto Tecnológico de Oaxaca. Su línea de investigación actual es desarrollo regional sustentable. Entre sus más recientes publicaciones, como coautor, se encuentran: "Ciudades: análisis de sus desigualdades inter e intraurbanas. El caso de Oaxaca, México 2000-2015", Bitácora Urbano Territorial, 28 (3), Bogotá, Universidad Nacional de Colombia, pp. 27-38 (2018); "Análisis del impacto de las pequeñas y medianas ciudades en el cambio climático. El caso de Oaxaca, México 2000-2015", Sociedad y Ambiente, 5 (14), San Cristóbal de las Casas, El Colegio de la Frontera Sur (Ecosur), pp. 99-1 18 (2017), y "Las redes de la vivienda y el desarrollo sustentable en la centralidad de las ciudades de Oaxaca, México, 2000-2015”, Estudios Demográficos y Urbanos, 32 (3), Ciudad de México, El Colegio de México, pp. 515-546 (2017).

Maribel Pérez Pérez. Doctora en Ciencias en Desarrollo Regional y Tecnológico en el Instituto Tecnológico de Oaxaca, México. Actualmente es profesora del Colegio de Estudios Científicos y Tecnológicos del Estado de Oaxaca. Su línea de investigación es desarrollo regional sustentable. Entre más recientes publicaciones, como coautora, destacan: "Educación media superior y desarrollo sustentable en las ciudades del estado de Oaxaca, México", Perfiles Educativos, 41 (163), Ciudad de México, Instituto de Investigaciones sobre la Universidad y la Educación, Universidad Nacional Autónoma de México, pp. 69-87 (2019); "Las redes de la vivienda y el desarrollo sustentable en la centralidad de las ciudades de Oaxaca, México, 2000-2015”, Estudios Demográficos y Urbanos, 32 (3), Ciudad de México, El Colegio de México, pp. 515-546 (2017), y “Análisis del impacto de las pequeńas y medianas ciudades en el cambio climático. El caso de Oaxaca, México 2000-2015”, Sociedad y Ambiente, 5 (14), San Cristóbal de las Casas, El Colegio de la Frontera Sur (Ecosur), pp. 99-118 (2017). 
Christian Martínez Olivera. Maestro en Ciencias en Desarrollo Regional y estudiante de Doctorado en Ciencias en Desarrollo Regional y Tecnológico en el Instituto Tecnológico de Oaxaca, México. Su línea de investigación actual es el desarrollo regional sustentable. Entre sus más recientes publicaciones, como coautor, se encuentran: "La gestión pública como herramienta de gobernanza para la generación de desarrollo local sustentable en las zonas metropolitanas de Oaxaca (México), periodo 2000-2017”, en Juan Antonio Márquez Domínguez y Jorge Luis Llamas Chávez (dirs.), Hélices y anclas para el desarrollo local, Huelva, Diputación de Huelva (España), Universidad de Cartagena de Indias (Colombia), Universidad de Huelva (España), pp. 365-373 (2019), y "Los conflictos sociales y su impacto en el turismo. El caso de las ciudades de Oaxaca, México", Investigación y desarrollo, 27 (1), Barranquilla, Universidad del Norte, pp. 107-136 (2019).

Karina Aidee Martínez García. Candidata a doctora en Ciencias en Desarrollo Regional y Tecnológico en el Instituto Tecnológico de Oaxaca, México. Sus líneas de investigación son desarrollo regional sustentable y la vivienda conectada. Entre sus más recientes publicaciones, como coautora, destacan: "Educación media superior y desarrollo sustentable en las ciudades del estado de Oaxaca, México", Perfiles Educativos, 41 (163), Ciudad de México, Instituto de Investigaciones sobre la Universidad y la Educación/Universidad Nacional Autónoma de México, pp. 69-87 (2019); "Ciudades: análisis de sus desigualdades inter e intraurbanas. El caso de Oaxaca, México 2000-2015”, Bitácora Urbano Territorial, 28 (3), Bogotá, Universidad Nacional de Colombia, pp. 27-38 (2018), y "Marginación y rezago social en ciudades de las regiones de pueblos originarios. El caso de Oaxaca en el sur de México", Espacio y Desarrollo, núm. 30, San Miguel Lima, Pontificia Universidad Católica del Perú, pp. 59-83 (2017). 